\title{
LASER USED IN PEDIATRIC DENTISTRY: A REVIEW
}

\author{
Avanindra Kumar ${ }^{1}$, Amit Kishor², Avanish Kumar ${ }^{3}$, Pushpa ${ }^{4}$, Md. Jawed Akhtar ${ }^{5}$
}

\section{HOW TO CITE THIS ARTICLE:}

Avanindra Kumar, Amit Kishor, Avanish Kumar, Pushpa, Md. Jawed Akhtar. "Laser Used In Pediatric Dentistry: A Review". Journal of Evolution of Medical and Dental Sciences 2015; Vol. 4, Issue 64, August 10;

Page: 11224-11231, DOI: 10.14260/jemds/2015/1616

INTRODUCTION: In 1960, Theodore Harold Maiman, an American of Hughes Aircraft corporation, observed the stimulated emission in the visible portion of the spectrum by using an excited synthetic ruby rod, and generated the first "LASER" beam an acronym for "Light Amplification by Stimulated Emission of Radiation".1 The acceptance of lasers as viable alternatives to traditional methods in medicine was one of the events that created an explosion of interest in the last decade in the role of lasers in dentistry. ${ }^{2}$ Dentistry has entered the 1990 s an era of high technology. We are fortunate to have at our disposal many technological innovations to enhance treatment, including intraoral video cameras, computer imaging, and air abrasive units. However no instruments are more representative of the term high-tech than the laser. ${ }^{3}$

The main principle in the application of laser is the use of light energy instead of rotation forces and sharp blades. It is also possible to remove caries without anesthesia or with less local anesthesia. Therefore, the dangers of lips and tongue bites which are frequent problems with children can be avoided. ${ }^{4}$ Laser-supported dental diagnosis and treatment, which allows us to meet the important aim of "filling without drilling," is an excellent approach from the tissue preservation point of view and, as reported by Martens and reiterated by Gutknecht, "children are the first in line to receive dental laser treatment".

So, Lasers are patient friendly; children and adolescents are the best candidates for laser use because they are especially bothered by pain, bleeding, incapacitation and a need for office visits for extensive postoperative care. 5

Types of Laser used in Pediatric Dentistry: Different lasers are used in pediatric dentistry. These lasers include caries detection lasers Diagnodent (Diode 655nm), argon lasers for composite curing, CO2 lasers with wavelength of $10600 \mathrm{~nm}$ for soft tissue surgeries, Nd: YAG lasers with wavelength of $1064 \mathrm{~nm}$ as well as Diode with wavelength of $810-980 \mathrm{~nm}$ for soft tissue cutting, the Erbium laser family including Er: YAG (2940nm) and Er; Cr: YSGG (2780nm) which are used in hard tissues, cavity preparation and in soft tissue surgery. And also Low Level Lasers which are used in stimulatory and inhibitory biologic process. ${ }^{6}$

Clinical Application of Laser: Laser has much potential application in pediatric dentistry, which are grouped into:

1. Soft tissue application.

2. Hard tissue application.

Frenectomy: Frenectomy is a procedure done in patients with a high maxillary fermium or lingual fermium attachment that causes midline diastema. Kim Kutsh, Anil S and Harvey Wigsoretal stated that laser could be used effectively in case of frenectomy.3,7,8 
Kotlow L stated that the best laser for treatment of this condition is Erbium laser, which is used simultaneously with water spray. This intervention is performed without need of sutures, scar tissue formation and any problem in healing. Usually frequencies between $30-45 \mathrm{~Hz}$ and energy between $35-55 \mathrm{~mJ}$ are used. Diode laser with power of $1 \mathrm{~W}$ in continuous mode can also be used, but it is essential to pay attention to the fact that with this method the possibility of damage to surrounding tissues, pain and discomfort after surgery is more than application of Erbium laser. ${ }^{9}$

Tounge Tie in Neonates and Older Children: Treatment of tongue tie in neonates with laser does not require sedation or local anesthetic. laser settings are Er: YAG 30hz, $50 \mathrm{mj}$, no water, Er, Cr: YSGG $20 \mathrm{hz}, 1$ watt, no water.in most cases, 8mm of freedom is adequate to allow for normal nursing. After treatment children can begin nursing and nursing mothers report immediate relief of pain, extended nursing intervals, and improve infant sleep duration. ${ }^{10}$

Older children are prepared in the usual manner; Er: YAG30hz and 50mj. The tongue is stabilized with hemostat and the fermium is revised. ${ }^{11}$

Pericoronal Problems in Erupting Teeth: It is not uncommon for children, whose first permanent molars are erupting to develop discomfort, swelling, or infection in tissue overlying the emerging tooth; teens and adults often experiences this with other teeth. Lasers can be used in a noncontact mode to ablate the involved tissue and expose the clinical crown of the involved tooth. In most instances the treatment with the laser can be completed without the use of local anesthesia. Erbium settings are $20-30 \mathrm{htz}$ and 45 to $55 \mathrm{mj}$ in a noncontact mode with no water. ${ }^{12}$
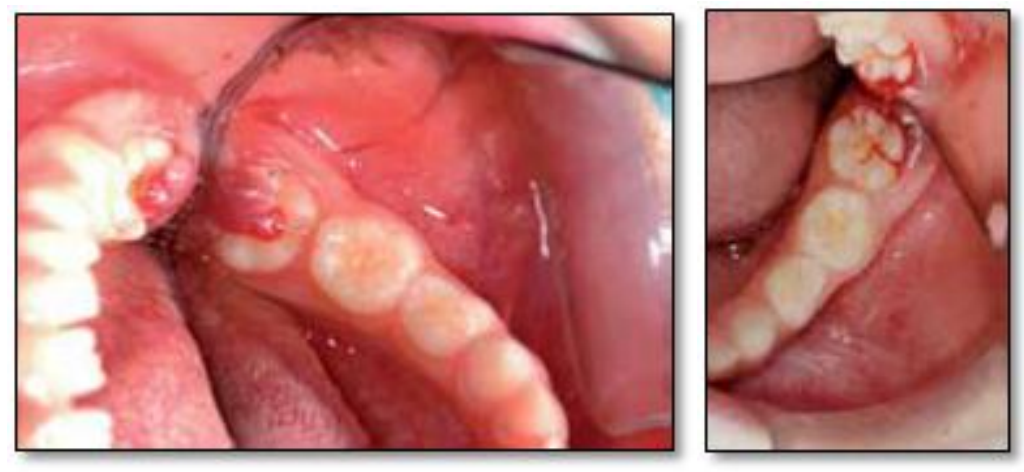

Patient, 6.2 years old. Due to 36 eruption hyperplastic tissue has formed. Immediately after erbium excision: laser-assisted gingivoplasty procedure.

Ankyloglossia: Lawrence A. Kotlow stated Ankyloglossia is a frequent finding in newborns, which can cause significant problems in terms of breast feeding, nutrition and speech if the adhesion is severe.it can be diagnosed in $3.2 \%$ pediatric patients.

For the treatment of this condition surgical lasers without need for anesthesia or sedatives are used. It is important to protect the infant and dentist's eyes with laser glasses and pay attention to the sublingual glands. ${ }^{13}$

Gingivectomy: In children with gingival hypertrophy, we can use various lasers for gingival remodeling. Gingival hypertrophy can be caused by some medications like Dilantin or by weak hygiene after orthodontic appliances have been set. 


\section{REVIEW ARTICLE}

Also in cases of tooth decay that propagated under the gingiva, it's possible to use laser to remove gingival tissue and proceed through repair stages without gingival hemorrhage. ${ }^{14}$ Lin PP and Cobb I. M suggested that with CO2 laser the excessive tissue is easily vaporized away or cut away with argon Nd: YAG or Ho: YAG wavelengths. ${ }^{15,16}$

For mentally handicapped children this is an outstanding modality because it allows for a relatively benign postoperative course for the patient who may not fully comprehend bleeding and pain. ${ }^{10}$

Lesions Removal and Biopsy: Soft tissue lesions in children and teenagers are clinical findings resulting from trauma, because in these ages traumas and blows are frequent. Between those lesions we can point the benign fibrotic lesions resulting from lip trauma. These lesions if pigmented can be removed by Argon,

Diode and Nd: YAG lasers. And if the lesions are not pigmented, it's easier to remove with Erbium and $\mathrm{CO} 2$ lasers, because these wavelengths are easily absorbed in water. Usually this operation needs local anesthesia, but rarely needs sutures. Advantages of laser in removal of these lesions are least hemorrhage. ${ }^{9}$ And post-surgical discomfort. In addition, the pathologist has to be informed that the lesion has been removed by laser, in order to make an accurate diagnosis. Erbium laser with mean energy of $55 \mathrm{~mJ}$ and frequency of $15-45 \mathrm{~Hz}$ as well as Diode laser with $1-1.5 \mathrm{~W}$ power can be used. For Diode laser, it is better to use them in well vascularized regions, in order to benefit from their hemostasis characteristic. ${ }^{17}$

Treatment of Aphthous Ulcers and Herpetic Lesions: Isolated aphthous ulcers or stomatitis, is one of the reasons of children impatience and agitation. ${ }^{18}$ The goal of treating apthous ulcer with a laser is to create a palliative effect on the lesion so that it will remain comfortable while normal healing occurs. ${ }^{19}$ Michael Clover and Paul Kujo in 1991 treated 25 separate minor recurrent apthous ulcer in 18 patients using 10 watt $\mathrm{CO} 2$ laser they noticed that sixteen patients of the 18 were completely pain free following resolution of the anesthesia. They concluded that $\mathrm{CO} 2$ laser could be induced as another tool in the treatment of the canker sore from recurrent apthous ulcer because laser's ability to reduce or eliminate pain. ${ }^{20}$

Herpes simplex virus infection of the lips is most common among adolescent. Symptoms can range from mild discomfort to extreme pain. In herpes labialis using the laser when the prodromal signs first appear has a palliative effect on the area and may prevent the development of a full herpes lesion from developing. ${ }^{11}$

Hard Tissue Application: Only a few years after the discovery of the first rubylasers, investigations were undertaken to introduce laser technology in dentistry for optical drilling of teeth and replacement of conventional treatments methods. ${ }^{21}$

Research on the effect of lasers on dental/hard tissues has carried out with various types of laser like Ruby, Helium-Neon, Carbon dioxide, Neodymium YAG/Glass, Er Bium, Excimer etc. ${ }^{22}$

Caries Detection: Early detection of dental caries is an important issue, since it may allow the clinician to use a preventive approach rather than a restorative one. Diagnodent is a caries detection tool, which is the Diode laser with wavelength of $655 \mathrm{~nm}$. The Diagnodent via emitted fluorescence from occlusal or proximal teeth surfaces shows a number that reflects the degree of demineralization 


\section{REVIEW ARTICLE}

of the teeth and the amount of decay. ${ }^{23} \mathrm{~A}$ recent study discovered that bacterial metabolites within caries produce fluorescence that can be enhanced by laser light. Quantitative laser fluorescence (QLF) is a method of measuring the induced tooth fluorescence and quantifying tooth demineralization and lesion severity. ${ }^{24}$

The argon and helium -cadmium laser are effective in detecting dental caries. Healthy enamel shows a characteristic luminescence the enamel affected with caries takes on a more chalky white appearance. This is due to the demineralization of the enamel hydroxyapatite by carious process. ${ }^{25}$ Bjelkhagen eta al 1982 used an argon laser for luminescence and was able to observe natural and artificial incipient demineralization areas as an earlier stage they could observe in bitewing radiographs. ${ }^{7}$

Pit and Fissure Therapy: The use of laser gives the dentist the ability to clean and sterilize enamel fissures. Studies have shown that enamel surface prepared with Erbium laser has properties similar to enamel etched with acid. The important point is to not move the Erbium laser in a way to produce more etch in a zone compared to other regions. ${ }^{26} 27$

Pit and fissures can be cleaned so thoroughly that sealing may not be necessary and there by reduces the use of resin sealing. The use resin sealing is reduced by fusing hydroxyl crystals in deep pit and fissure areas. It has been found that lasing caused melting or dissolution of surface structure. Subsequent recrystallization takes place in the presence of fluoride upon cooling with the formatting of Fluor appetite which was less soluble than the original enamel apatite and could their prevent dental caries. ${ }^{22}$

The CO2 laser can remove the organic and inorganic debris found in pits and fissures. ${ }^{25 \mathrm{Zhang}}$ S.et al 1992 determined the inhibition of demineralization of enamel fissures by combined laser/fluoride treatment. They noticed significant inhibition of further lesion progression and indicated that $\mathrm{CO} 2$ has potential use in the treatment of pit and fissures. ${ }^{28}$

Sealant Placement: Terry D. Myers and Willium (1985) investigated the effect of pulsed Nd: YAG laser on enamel fissures. Thirty recently extracted teeth with pit and fissure incipient lesions were used for the study. They found that Nd: YAG laser has the potential to remove organic and inorganic debris from the pits and fissures without causing pulpal or enamel injury due to the minimal laser energy. They suggested that this type of laser could be used as a desirable step in sealant therapy. ${ }^{29}$

Etching: There were some important differences between the results of various studies in evaluation of the bond strength of restorative material bonded to teeth surfaces etched with Erbium laser family and with acid etch technique. These differences could be the results of laser parameters (Output energy and frequency) and the type of restorative material used. The obtained SEM images showed an increase in retention of restorative material for the surfaces irradiated by laser and a decrease in bacteria in the pits and fissures, the sterilization property of laser on irradiated surfaces is seen. In general, the best results have been obtained in

Simultaneous use of laser and acid 30

Pulpcapping and Pulpotomy: Today substances like for mocresol are used in deciduous teeth pulp therapies, which smell disturbs children, but also its contact with mucosal surfaces can cause necrosis and ulcers that are very unpleasant and painful for children. ${ }^{31}$ Studies have shown that laser 


\section{REVIEW ARTICLE}

have good effects in pulp therapy, which results are similar or even better than for mocresol. Taking into account the many advantages of laser compared to conventional methods, like hemostasis, preservation of living tissues near the tooth apex, absence of vibrations and smells, satisfaction of children and parents are more guarantied. Concerning the use of laser in pulp therapy, one of its main advantage and perhaps actually more important is its safety compared to other conventional methods and their possible side effects, especially concerning for mocresol which is strongly criticized in the literature. $\mathrm{Nd}$ : YAGlaser with output power of $2 \mathrm{~W}$ and frequency of $20 \mathrm{~Hz}$ and Erbium laser with power of $0.5 \mathrm{~W}$ and frequency of $20 \mathrm{~Hz}$ can be used for this purpose. ${ }^{32}$
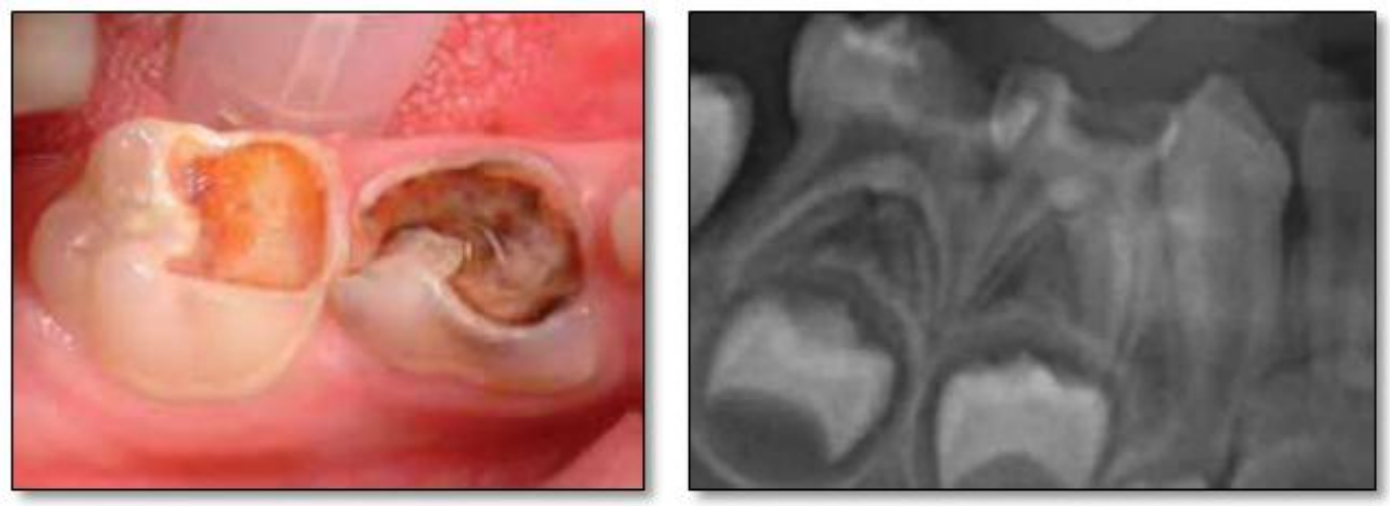

Female patient, 5.2 years old. Deep caries on molar teeth \& X-ray view.
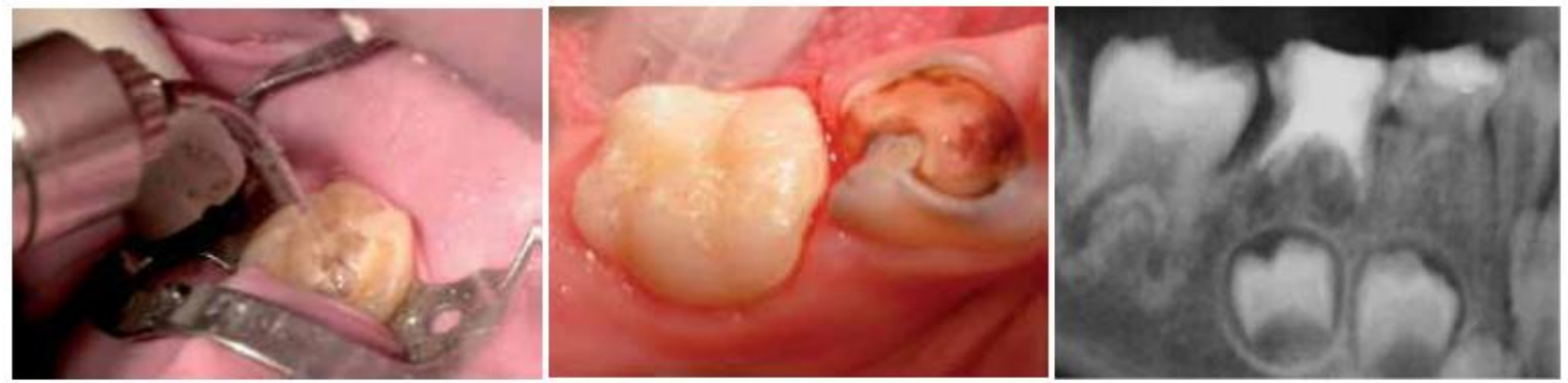

Endodontic treatment is performed by using an Er: YAG laser $(300 \mu \mathrm{m}$ tip at 70 to $75 \mathrm{~mJ}, 20 \mathrm{~Hz}$ and 1.4 to $1.5 \mathrm{~W}$ ). Parameters are reduced in the middle third and the cavity is filled with ZOE and a thin layer of glass ionomer cement. Color and morphology are restored by the anatomical layering technique. Post-treatment X-ray.

Low Level Laser Application in Pediatric Dentistry: The different types of low level lasers are red visible Helium Neon (He-Ne), invisible infra-red Gallium- Arsenide (Ga-As), Gallium-AluminumArsenide (GaAlAs), Indium-Gallium-Aluminum- Phosphide (InGaAlP). Low level lasers act on target tissues via photochemical and photobiological effects. Low level lasers produce between 50-500mw power and have stimulatory as well as inhibitory effects. Their application in pediatric dentistry include anesthesia, traumatized anterior teeth treatment, muscle spasms and cellulitis treatment, temporomandibular joint problems treatment, attenuation of Gag reflex and reduction of postsurgical complications. ${ }^{33}$ 
CONCLUSION: Laser works on the principal of monochromatic coherent and collimated radiation by a suitable laser medium in an optical resonator. Modern pediatric dentistry must take the advantage of all new advances, until an equilibrium is achieved between novelty effect, effectiveness, replacement of old treatments, modification of old techniques to improve the standard of care of children and adolescents. The objective of pediatric dentistry treatments is preventive or repair treatments on mouth or teeth in a stress and pressure free environment. Since the control of children behavior and the reduction of the work time are some of the important pillars in pediatric dentistry, it seems that the use of lasers can be very beneficial. The most commonly used lasers in dentistry can lessen the stress and fear of patients during dental operations. They are more conservative methods on soft and hard tissues, with minimal discomfort and hemorrhage.

\section{REFERENCES:}

1. Mercer C. Lasers in dentistry: A review. Part 1. Dental update 1996 March; 74-78.

2. Miserendino LJ, Pick RM. Lasers in dentistry. Chicago: Quintessence publications 1995

3. Kim Kutsh Laser in dentistry: Comparing Wavelength. JADA 124:49-54: Feb: 1993[39].

4. Martens LC. Laser-assisted pediatric dentistry: review and outlook. J Oral Laser Applications 2003; 3(4):203-9.

5. Boj JR. The future of laser pediatric dentistry. J Oral Laser Applic 2005; 5:173-77.

6. Koci E, Almas K. Laser applications in dentistry: an evidenced-based clinical decision-making update. Pakistan Oral \& Dental Journal 2009; 29(2):409-23.

7. Anil S. et al "Laser application in dentistry" JIDA 63:3:101-106 March 1992[26].

8. Harvey Wigsor et al "The effect of laser on dental hard tissue "JADA 124:65-70: Feb: 1993[36].

9. Kotlow L. Pediatric dentistry begins at birth: lasers and pediatric dental care in treating soft tissue lesions in the dental office. J Pediatr Dent Care 2007; 13: 12-6.

10. Rober M Pick “Using laser in clinical dental practice”JADA 124:37-47: Feb 1993. [37].

11. Lawrence A. Kotlow "Lasers in pediatric dentistry", Dent Clin N Am48 (2004)889-922[107].

12. Guelman M, Britto LR, Katz J. Cyclosporine induced gingival overgrowth in a child treated with C02 laser surgery: a case report. J Clin Pediatr Dent 2003; 27(2):123-6.

13. Kotlow LA. Ankyloglossia (tongue-tie): a diagnostic and treatment quandary. Quintessence Int 1999; 30(4):259-62.

14. Guelman M, Britto LR, Katz J. Cyclosporine induced gingival overgrowth in a child treated with CO2 laser surgery: a case report. J Clin Pediatr Dent 2003; 27(2):123-6.

15. Lin PP et al "The effect of pulsed Nd: YAG laser on periodontal pockets following sub gingival application" J Dent Res.71:299:1992[29]

16. Cobb I.M. et al "The effect of CO2, ND: YAG and qIEr: YAG lasers with and without surface coolant on tooth root surface" J. Clin. Periodontal.24:55-60:1997[55].

17. Kotlow LA. Lasers in pediatric dentistry. Dent Clin North Am 2004;48(4):889-92

18. Parkins F, O Toole T, Yancy J. Laser treatments of aphthous and herpetic lesions. J Dent Res 1994; 73:190.

19. Stuart Coleton "Laser in surgical periodontics and oral medicine" Dent Clin N Am 48(2004)937962[109]

20. Michael Clover and Paul Kuo "Managing Apthous ulcer: Laser treatment applied" JADA.122:5153June1991

21. Kenneth L. Zakariasen “Sheading New Light on Lasers” JADA 124:30-32;Feb.1993 
22. Berry H H et al "Holmium: YAG Laser Arthroscopy of the tempromemdibularjoint". J. Oral Maxillofacial Surg.50:931-934:1992

23. Bader JD, Shugars DA. A systematic review of the performance of a laser fluorescence device for detecting caries. J Am Dent Assoc 2004; 135(10):1413-26.

24. Jie Yang, Vinicus Dutra "utility of radiology, laser fluorescence and transillumination" Dent Cin N Am 49(2005) 739-752

25. J.D.B. Featherstone and D.G.A. Nelson "lessor effects on dental hard tissues', J. Endodontics 11(9): 379-383:1985

26. Frentzen M, Santaella MRLA, Matson E. Er: YAGlaserassisted fissure sealing. International Congress Series 2003; 1248:197- 8.

27. Lupi-Pégurier L, Bertrand M, Genovese O, Rocca JP, Muller-Bolla M. Microleakage of resin-based sealants after Er: YAG laser conditioning. Lasers Med Sci 2007; 22(3):183-88.

28. Zalewska J and Objeta D "use of low energy laser as adjunct treatment of alcohol addiction" laser in medical science (2004) 19:100-104.

29. Terry D Myers and William D. Myers "The use of a laser for debridement of incipient caries" J. of Prosth Dent.53(6):776-778:june 1985

30. Borsatto MC, Corona SA, Dibb RG, Ramos RP, Pecora JD. Microleakage of a resin sealant after acid-etching, Er: YAG laser irradiation and air-abrasion of pits and fissures. J Clin Laser Med Surg 2001; 19(2):83-7.

31. Toomarian L, Fekrazad R, Sharifi R, Baghaei M, Rahimi H, Eslami B. Histopathological evaluation of pulpotomy with Er, Cr: YSGG laser vsformocresol. Lasers Med Sci 2008; 23(4):443-50.

32. Kotlow L. Use of Er: YAG laser for pulpotomies in vital and nonvital primary teeth. J Laser Dent 2008; 16(2):75-9.

33. Walsh LJ. The current status of low level laser therapy in dentistry. Part 1 soft tissue applications. Aust Dent J1997; 42(4):247-54. 


\section{AUTHORS:}

1. Avanindra Kumar

2. Amit Kishor

3. Avanish Kumar

4. Pushpa

5. Md. Jawed Akhtar

\section{PARTICULARS OF CONTRIBUTORS:}

1. Senior Lecturer, Department of Oral Pathology, Dr. B. R. Ambedkar Dental College, Patna, Bihar, India.

2. Senior Lecturer, Department of Pedodontics and Preventive Dentistry, Dr. B. R. Ambedkar Dental College, Patna, Bihar, India.

3. Additional Professor, Department of Anatomy, Indira Gandhi Institute of Medial Sciences, Sheikhpura, Patna, Bihar, India.

\section{FINANCIAL OR OTHER} COMPETING INTERESTS: None
4. Senior Lecturer, Department of Pedodontics and Preventive Dentistry, Dr. B. R. Ambedkar Dental College, Patna, Bihar, India.

5. Senior Resident, Department of Anatomy, Indira Gandhi Institute of Medical Sciences, Sheikhpura, Patna, Bihar, India.

\section{NAME ADDRESS EMAIL ID OF THE CORRESPONDING AUTHOR:}

Dr. Avanindra Kumar, Senior Lecturer,

Department of Oral Pathology, Dr. B. R. Ambedkar Dental College, Patna-800014, Bihar, India

E-mail: simsavanish.yt@gmail.com

Date of Submission: 14/07/2015. Date of Peer Review: 15/07/2015. Date of Acceptance: 03/08/2015. Date of Publishing: 08/08/2015. 